\title{
Using Fuzzy Approach for Solving Multi-Level Problem in Egyptian Upstream Gateway
}

\author{
O.E. Emam \\ Dean of Faculty of Computers and \\ Artificial Intelligence \\ Helwan University \\ Cairo, Egypt
}

\author{
Sayed Abdelgaber \\ Vice Dean Faculty of Computers \\ and Artificial Intelligence \\ Helwan University \\ Cairo, Egypt
}

\author{
N.M. Ahmed \\ Teaching Assistant \\ Faculty of Business, Canadian \\ International College $(\mathrm{CIC})$ \\ Cairo, Egypt
}

\begin{abstract}
In 2020, an agreement was signed between Egyptian Ministry of Petroleum \& Schlumberger, i.e., International petroleum Service Company, to collaborate to form a world-class National Data Repository (NDR) for Egyptian Upstream data that will preserve, develop, promote, and maximize the value of the country's big data related to the petroleum Exploration and Production (E\&P) sector. The project aims to digitally promote Egypt's oil and gas industry through seamless online access to the oil and gas sector's data.

This innovative project aims to attract the International Oil Companies (IOCs) investors worldwide to accelerate Egypt's discoveries and hence increase both the daily hydrocarbon production as well as oil and gas country reserves.

In this study, there are three levels of decision makers; the first level will be the Egyptian Ministry of Petroleum where its main goal is to increasing the country oil and gas production while the second decision maker level i.e. Schlumberger which is looking for achieve a prosperous longterm project in Egypt, the third level decision maker will be the International Oil Companies (IOCs) that will invest in Egypt to accomplish a new hydrocarbon discoveries and minimize the Exploration risk by increasing the exploration success rate. The Italian Eni company is one of the most interested international companies that looking to invest more in the energy sector of Egypt after the discovery of the giant Zohr gas field in 2015 and it will be a symbolic for the third level decision maker in this article.

By applying the Fuzzy approach, all decision maker levels reach to a high satisfaction level i.e., $\delta=0.999$ regarding their objectives and goals by using this innovative EUG project.
\end{abstract}

\section{General Terms}

Multi-level programming, Operation research (OR), Egypt Upstream Gateway (EUG).

\section{Keywords}

Multi-level programming, linear programming, operation research, Egypt upstream Gateway, Egypt petroleum exploration \& production, Fuzzy Approach.

\section{INTRODUCTION}

In general, oil and gas industry subdivided into three main sectors: upstream (including exploration and development and hydrocarbon production), midstream (dealing with transportation and processing) and downstream (dealing with distribution and sale to the end users /consumers) as shown in fig. 1

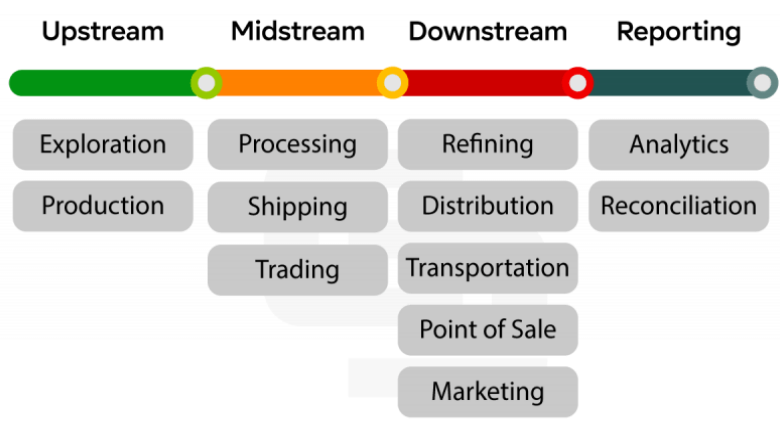

Figure 1": Display the three main oil and gas sectors.

This figure illustrates Upstream, Midstream and Downstream hydrocarbon sectors. The upstream sector includes all the activities related to petroleum exploration, development and hydrocarbon production.

Adebayo \& Tawabini mentioned that upstream is a term for the operations stages in the oil and gas industry that involve exploration and production. Petroleum exploration phase requires very sophisticated expensive techniques, and the technology available for petroleum exploration is rapidly advancing. Once the hydrocarbons have been extracted, the upstream part of the business is over. Midstream companies focus on the storage and transportation of the crude oil and natural gas through pipeline, railway, or tanker truck to refineries. Refineries are the downstream phase of the oil and gas industry. They process the raw crude oil into their end usable products such as gasoline. They also sell and distribute natural gas and the products that are derived from crude oil [1].

Egypt is a mature oil \& gas producer having long history in hydrocarbon exploration and production for more than a century. The government of Egypt has managed over time to maintain sufficient interest in the exploration upside via reasonable investment terms and a vibrant operating environment [2].

The Egyptian Ministry of Petroleum and Schlumberger introduce the Egypt Upstream Gateway (EUG), a unique and innovative national project for digitizing subsurface upstream information and delivering a digital subsurface platform. This agreement will be seven years duration. This upstream digital platform aims to attract new investments to Egypt from investors all around the world through state-of-the-art bid round digital enablement (Egypt Oil \& Gas newspaper, 2020). 
The project will be a platform to promote Egypt's exploration and production potential worldwide. It depends on creating the information infrastructure and digitizing data by reconverting all old technical data of the National and International operating companies in Egypt from paper form or old storage media that are not commensurate with technological development to the modern digital platform using the latest technologies to continuously save and secure data.

The term Operations Research (OR) refers to a discipline that focuses on using information technology to make better decisions. To put it another way, OR is the analysis of optimum resource distribution. OR's aim is to give decision makers a logical reason for making decisions. Attempting to fully understand and organise complex problems in order to predict system behaviour and enhance the system's performance. Most of the actual work is done by developing and manipulating mathematical models of organisational systems made up of individuals, tools, and procedures using analytical and numerical techniques.

One of the most main characteristics of an Operations Research is its focus on the whole problem. This means that every action by every part of an organisation has an impact on the behaviour of any other part of the organisation.

In order to make any decision, decision makers have to determine all potential interactions and evaluate their effect on the organisation as a whole [3].

Operations research makes a difference in enhancing an organization's productivity. It makes a difference in making a decision on the location, structure, budget of industrial facilities, manufacturing facilities, and other facilities. Simply, OR can be used for any scenario to enhance the efficiency of the organization [4].

Multi-level programming (MLP) is a powerful analytical tool, it's more computationally difficult and costly than traditional mathematical programming. MLP has the potential to be effective for the whole organization [5].

MLP has been proposed for managing with decision processes involving three decision makers with a hierarchical structure. The first level's decision maker is known as the leader, the second level's decision maker is concerned with the first level goal, and the third level's decision maker is concerned with the second level goal. Each decision maker strives to maximise his or her own objectives [6].

Multilevel optimization problems are mathematical programming problem in which the feasible set is defined implicitly by a series of nested optimization problems. These sorts of problems are typical in a wide range of applications involving a hierarchy of decision makers [7].

The basic premise of a multi-level programming strategy is that the first-level decision maker (FLDM) states his goal, which needs each subordinate level within the organisation to come up with an autonomous optimal solution. The FLDM adjusts these arrangements in accordance with the organization's goals. This procedure leads to a satisfying result [8].

Multi-level programming problems (MLPP) arise in multilevelled associations with multiple decision makers (DL) to resolve autonomous programming challenges where each DL independently controls a large number of choice criteria. DL must have a bargaining and agreeable inspiration in order to guarantee a solution for the association's overall benefit [9].

Numerous amounts of research have been published on multilevel programming problems (MLPPs) for hierarchical decentralised planning problems, and various methodologies to solve MLPPs have been proposed.

T. I. Sultan mentioned a three-level large-scale linear programming problem in which the objective functions must be maximised at each level. A three-level programming problem can be considered as a static version of the Stackelberg strategy. The researchers developed a method to solve a three-planner model, and there were able to come up with a solution to this problem. They used Dantzig and Wolfe decomposition method, at each level they attempted to optimize its problem separately as a large-scale programming problem [10].

Lai and Hwang at first developed an effective fuzzy approach using the concept of tolerance membership functions for solving MLPPs, Lai used this concept for solving multi-level linear programming problems (ML-LPPs) [11].

This paper is settled as follows: In Sector 2 introduce the problem formulation. In Sector 3 a brief about Egypt Upstream Gateway (EUG) case study. In Sector 4, discussing fuzzy approach and its algorithm. In Sector 5, applying our algorithm on the numerical example. Lastly, Section 6 conclusion and our summary.

\section{PROBLEM FORMULATION AND SOLUTION CONCEPT}

The TLLPP with parameters in the objective functions may be formulated as follows:

[first level]

$\max _{X_{1}} F_{1} \approx \sum_{j=1}^{n} \tilde{c}_{1 j} x_{j}$,

where $x_{2}, x_{3}$ solves

[second level]

$\max _{X_{2}} F_{2} \approx \sum_{j=1}^{n} \tilde{c}_{2 j} x_{j}$,

where $x_{3}$ solves

\section{[Third level]}

$\max _{X_{3}} F_{3} \approx \sum_{j=1}^{n} \tilde{c}_{3 j} x_{j}$

Subject to

Were

$G=\left\{\left(x_{1}, x_{2}, x_{3}\right) \lg \left(x_{1}, x_{2}, x_{3}\right) \leq 0, i=\right.$ $1,2, \ldots \ldots . n\}$,

(4)

Where $G$ is the three-level convex constrain, therefore $f_{i}: R^{m} \rightarrow R,(i=1,2,3) \quad$ indicates the first-level objective function, second-level objective function, and thirdlevel objective function, separately. Additionally, the first- 
level decision maker (FLDM) has $x_{1}$, representing the first decision level choice; as well as the second-level decision maker (SLDM) and the third-level decision maker (TLDM) have $x_{2}$ and $x_{5}$, representing the second decision level choice and the third decision level choice, respectively

\subsection{Definition 1}

For any $\left(x_{1} \in G_{1}=\left\{x_{1}, \mid\left(x_{1}, \ldots, x_{n}\right) \in G\right\}\right)$ given by the FLDM and $\left(x_{2} \in G_{2}=\left\{x_{2}, \mid\left(x_{1}, \ldots, x_{n}\right) \in\right.\right.$ $G\})$ given by the SLDM, if the decision-making variable $\left(x_{5} \in G=\left\{x_{5}, \mid\left(x_{1}, \ldots, x_{n}\right\}\right)\right.$ is the optimal solution of the TLDM, then $\left(x_{1}, \ldots, x_{n}\right)$ is a feasible solution of the TLLPP.

\subsection{Definition 2}

If $\left(x_{1}^{*}, x_{2}^{*}, x_{3}^{*}\right)$ is a feasible solution of the TLLPP problem; no other feasible solution

$\left(x_{1}, x_{2}, x_{3}\right) \in G$ exists, such that $f_{1 j}\left(x_{1}^{*}, x_{2}^{*}, x_{3}^{*}\right) \leq$ $f_{1 j}\left(x_{1}, x_{2}, x_{3}\right)$ with at least one $j\left(j=1,2, \ldots, N_{1}\right)$,so $\left(x_{1}^{*}, x_{2}^{*}, x_{3}^{*}\right)$ is the Pareto optimal solution of the TLLPP problem.

\section{CASE STUDY}

Egypt Upstream Gateway (EUG) will facilitates the process of purchasing packages of technical upstream data for IOCs for each specific interest available regions through the tenders issued by the Egyptian Ministry of Petroleum without the need for companies to come to Egypt, leading to a speedy completion of procedures for investment in the field of exploration and providing the opportunity for the largest number of international companies to obtain data packages and apply for petroleum auctions.

The Italian Eni company is one of the most interested international companies that looking to invest more in the energy sector of Egypt after the discovery of the giant Zohr gas field in 2015 and it will be a symbolic for the third level decision maker in this article.

Access to Egyptian upstream data helps accelerate decision making and reduce exploration turnaround time for operators more efficiently than ever before. Similarly, prospecting and licensing rounds are enhanced as the availability of quality data is continually improved. With this step, Egypt joins the league of countries that can effectively compete in the global energy E\&P sector.

Three main petroleum provinces are recognized in Egypt; the Gulf of Suez oil province, the north Western Desert oil province and the Nile Delta gas province. However, the Nile Delta and Mediterranean Sea, are still unexplored enough with anticipated large volumes of hydrocarbon resources [2].

The Nile Delta both onshore and offshore basin contains a thick sequence of potential hydrocarbon source rocks that generate essentially gas and condensate [12],[13],[14]. The offshore Nile delta exploration activities in the Mediterranean deep water are more expensive and riskier relative to onshore Nile Delta [15].

In 2015, the giant Zohr gas field was discovered by Eni in the deep water of the Mediterranean Sea, some $160 \mathrm{~km}$ to the NE of Port Said city. The field was classified as the world's largest gas find during that year as it was estimated to host substantial in-place gas volumes of 30 trillion cubic feet [16].

Recently Eni's CEO and board members decided that the company will continue to inject new investments and develop its business in Egypt in the coming period, especially as Egypt represents one of the most important areas for the company's activity. He mentioned that Eni seeks to pump investments of $\$ 3$ billion in Egypt during the upcoming period. The main objective of the company is to win the exploration license for four onshore concessions and two offshore deep-water concessions in the Nile Delta Province. This Eni plan will be our case study and it will be analysed in detail.

\section{FUZZY DECISION MODELS FOR TLN-MODM PROBLEM}

The three-planner Stakelberg and the well-known fuzzy decision model of Sakawa were used to solve the TLNMODM. After obtaining a satisfactory solution that is acceptable to FLDM, the SLDM is given the FLDM decision factors and goals, together with some tolerance, to pursue the satisfying solution [5].

The SLDM then gives the TLDM the decision variables and goals, together with some tolerance, to find the suitable solution and arrive at the solution that is closest to the FLDM's satisfactory solution.

This is because the TLDM should not only optimize the objective functions but also aim to meet the SLDM's goals and preferences as much as possible, and the SLDMs should do the same, to satisfy the FLDM's goals and preferences as much as possible.

\subsection{FLDM problem:}

The three-planner Stakelberg and the well-known fuzzy decision model of Sakawa were used to solve the TLNMODM. After obtaining a satisfactory solution that is acceptable to FLDM, the SLDM is given the FLDM decision factors and goals, together with some tolerance, to pursue the satisfying solution [5].

The SLDM then gives the TLDM the decision variables and goals, together with some tolerance, to find the suitable solution and arrive at the solution that is closest to the FLDM's satisfactory solution.

This is because the TLDM should not only optimize the objective functions but also aim to meet the SLDM's goals and preferences as much as possible, and the SLDMs should do the same, to satisfy the FLDM's goals and preferences as much as possible.

First, the FLDM solves the following:

$$
\begin{aligned}
& \max _{\bar{x}} f_{1}\left(\overline{x)}=\max _{\bar{x}}\left(f_{11}(\bar{x}), \ldots \ldots f_{1 N_{1}}(\bar{x})\right),\right. \\
& \text { s.t } \quad \bar{x} \in G
\end{aligned}
$$

Where

$$
\bar{x}=\left(x_{1}, x_{2}, x_{3}\right), \quad \bar{x} \in R^{n_{1}+n_{2}+n_{3}}
$$


Goals and tolerances should be defined before creating membership functions. For each of the five objectives, we need first determine the individual best $\left(f_{1 a}^{*}\right)$ and worst $\left(f_{1 \bar{a}}^{-}\right)$ solutions.

$f_{1 a}^{*}=\operatorname{Max}_{\bar{x} \in G} f_{1 a}(\bar{x}), f_{1 a}^{-}(\bar{x})=\min _{\bar{x} \in G} f_{1 a}(\bar{x})$,
$a=1,2, \ldots \ldots ., N_{1}$

The differences between the best and worst solutions, can then be set with reasonable goals and tolerances. The following membership functions of fuzzy set theory can be used to express this data.

$$
\begin{aligned}
& \mu_{f_{1 a}}\left[f_{1 a}(\bar{x})\right] \\
& =\left\{\begin{array}{cc}
1 & \text { if } f_{1 a}(\bar{x})>f_{1 a}^{*}, \\
\frac{f_{1 a}(\bar{x})-f_{1 a}^{-}}{f_{1 a}^{*}-f_{1 a}^{-}} & \text {if } f_{1 a}^{-} \leq f_{1 a}(\bar{x}) \leq f_{1 a}^{*} \\
0 & \text { if } f_{1 a}^{-} \geq f_{1 a}(\bar{x}) .
\end{array}\right.
\end{aligned}
$$

The solution of FLDM problem can be solved by the following Tchebycheff problem

\section{$\max \lambda$}

$$
\begin{aligned}
& \quad \begin{array}{l}
\text { Subject to } \\
\bar{x} \in G \\
\mu_{f_{1 a}}\left[f_{1 a}(\bar{x})\right] \geq \lambda, \quad a=1,2, \ldots \ldots, N_{1}
\end{array} \\
& \text { The expected solution is } \quad \lambda \in[0,1] . \\
& {\left[x_{1}^{F}, x_{2}^{F}, x_{3}^{F}, f_{1 k}^{F}, \quad a=\right.} \\
& \left.1,2, \ldots \ldots, N_{1}, \lambda^{f} \text { (Satisfactory level) }\right]
\end{aligned}
$$

\subsection{SLDM problem:}

The SLDM follows the same steps as the FLDM until reaches solution for its objectives, which is supposed to be

$$
\begin{aligned}
& \quad \max _{\bar{x}} f_{2}(\bar{x}) \\
& =\max _{\bar{x}}\left(f_{21}(\bar{x}), \ldots \ldots, f_{2 a}(\bar{x})\right), \\
& \quad d=1,2, \ldots \ldots, N_{2} \\
& \text { s.t } \quad \bar{x} \in G
\end{aligned}
$$

Where

$$
\bar{x}=\left(x_{1}, x_{2}, x_{3}\right), \quad \bar{x} \in R^{n_{1}+n_{2}+n_{3}}
$$

Determine the individual best $\left(f_{2 d}^{*}\right)$ and worst $\left(f_{2 d}^{-}\right)$ solutions for each objective.

$$
f_{2 d}^{*}=\operatorname{Max}_{\bar{x} \in G} f_{2 d}(\bar{x}), f_{2 d}^{-}(\bar{x})=\operatorname{Min}_{\bar{x} \in G} f_{2 d}(\bar{x}),
$$$$
d=1,2, \ldots \ldots, N_{2} \text {. }
$$

The following membership functions of fuzzy set theory can be used to express this data.

$$
\begin{aligned}
& \mu_{f_{2 d}}\left[f_{2 d}(\bar{x})\right] \\
& =\left\{\begin{array}{rr}
1 & \text { if } f_{2 d}(\bar{x})>f_{2 d}^{*} \\
\frac{f_{2 d}(\bar{x})-f_{2 d}^{-}}{f_{2 d}^{*}-f_{2 d}^{-}} \quad \text { if } f_{2 d}^{-} \leq f_{2 d}(\bar{x}) \leq f_{2 d}^{*} \\
0 \quad \text { if } \quad f_{2 d}^{-} \geq f_{2 d}(\bar{x}), \quad d=1,2, \ldots, N_{2} .
\end{array}\right.
\end{aligned}
$$

The solution of SLDM problem can be solved by the following Tchebycheff problem

$$
\max \beta
$$

Subject to

$$
\begin{aligned}
& \quad \begin{array}{l}
\bar{x} \in G, \\
\mu_{f_{2 a}}\left[f_{2 d}(\bar{x})\right] \geq \beta, \quad d=1,2, \ldots \ldots, N_{1}
\end{array} \\
& \qquad \beta \in[0,1] . \\
& \text { The expected solution is } \\
& {\left[x_{1}^{s}, x_{2}^{s}, x_{3}^{s}, f_{2 d}^{s}, \quad d=\right.} \\
& 1,2, \ldots, N_{2,} \beta^{s}{ }_{(\text {Satisfactory level) }]}
\end{aligned}
$$

\subsection{TLDM problem:}

The TLDM follows the same steps as the FLDM and SLDM until reaches solutions for its objectives, which is supposed to be

$$
\begin{gathered}
\max _{\bar{x}} f_{3}(\bar{x})=\max _{\bar{x}}\left(f_{31}(\bar{x}), \ldots \ldots f_{3 e_{1}}(\bar{x})\right), \\
e=1,2, \ldots \ldots, N_{3}
\end{gathered}
$$

s.t $\quad \bar{x} \in G$

Where

$$
\bar{x}=\left(x_{1}, x_{2}, x_{3}\right), \quad \bar{x} \in R^{n_{1}+n_{2}+n_{3}}
$$

Determine the individual best $\left(f_{3 e}^{*}\right)$ and worst $\left(f_{3 e}^{-}\right)$ solutions for each objective.

$f_{3 e}^{*}=\operatorname{Max}_{\bar{x} \in G} f_{3 e}(\bar{x}), f_{3 e}^{-}(\bar{x})=\operatorname{Min}_{\bar{x} \in G} f_{3 e}(\bar{x})$, $e=1,2, \ldots \ldots, N_{3}$.

The following membership functions of fuzzy set theory can be used to express this data.

$\mu_{f_{3 e}}\left[f_{3 e}(\bar{x})\right]$
$=\left\{\begin{array}{c}1 \\ \frac{f_{3 e}(\bar{x})-f_{3 e}^{-}}{f_{3 e}^{*}-f_{3 e}^{-}} \quad \text { if } f_{3 e}^{-} \leq f_{3 e}(\bar{x}) \leq f_{3 e}^{*} \\ \text { if } f_{3 e}(\bar{x})<f_{3 e}^{-}, \quad e=1,2, \ldots, N_{3} .\end{array}\right.$

The solution of TLDM problem can be solved by the following Tchebycheff problem

Subject to

\section{$\max \gamma$}

$$
\bar{x} \in G,
$$$$
\mu_{f_{3 e}}\left[f_{3 e}(\bar{x})\right] \geq \gamma,
$$

$$
\begin{aligned}
& \quad e=1,2, \ldots \ldots, N_{3} \\
& \gamma \in[0,1]
\end{aligned}
$$

The expected solution is

$$
\left[x_{1}^{T}, x_{2}^{T}, x_{3}^{T}, f_{3 e}^{T}, \quad e=1,2, \ldots \ldots, N_{3}, \gamma^{T}\right.
$$


(Satisfactory level)]

\section{NUMERICAL EXAMPLE}

[First Level]

$$
\begin{gathered}
\max _{X_{1}} F_{1} \approx\left[X_{1}+X_{2}+X_{3}+X_{4}+X_{5}+X_{6}\right. \\
\left.+X_{7}+X_{8}\right]
\end{gathered}
$$

Where $x_{1}$ solves

[Second Level]

$$
\begin{gathered}
\max _{X_{2}} F_{2} \approx\left[X_{2}+X_{4}+2 X_{5}+2 X_{6}+2 X_{7}\right. \\
\left.+2 X_{8}\right]
\end{gathered}
$$

Where $x_{2}$ solves

[Third Level]

$$
\begin{gathered}
\max _{X_{5}} F_{3} \approx\left[X_{1}+X_{2}+X_{3}+X_{4}+4 X_{5}+4 X_{6}\right. \\
\left.+4 X_{7}+4 X_{8}\right]
\end{gathered}
$$

Subject to

$x_{5}+x_{6}+x_{7}+x_{8} \widetilde{\leq} 1000$,

$x_{1}+x_{2}+5 x_{5}+5 x_{6} \widetilde{\simeq} 2800$,

$7 x_{1}+7 x_{2}+7 x_{3}+3 x_{5}+3 x_{6}+3 x_{7} \simeq 100$,

$x_{1}, x_{2}, x_{3}, x_{4}, x_{5}, x_{6}, x_{7}, x_{8} \geq 0$

In this example, will solve a three linear programming problem TLLPP problem

First step:

Fuzzy Approach will be applied to solve TLNLPP programming problem.

A) In this step will get the best and worst solution for each objective function at the first level, so it will solve the below equations individual:

$$
\begin{gathered}
\max _{X_{1}} F_{1}=X_{1}+X_{2}+X_{3}+X_{4}+X_{5}+X_{6} \\
+X_{7}+X_{8}
\end{gathered}
$$

Subject to

$$
\begin{gathered}
x_{5}+x_{6}+x_{7}+x_{8} \widetilde{\leq} 1000, \\
x_{1}+x_{2}+5 x_{5}+5 x_{6} \widetilde{\leq} 2800, \\
7 x_{1}+7 x_{2}+7 x_{3}+3 x_{5}+3 x_{6}+3 x_{7} \widetilde{\leq} 100, \\
x_{1}, x_{2}, x_{3}, x_{4}, x_{5}, x_{6}, x_{7}, x_{8} \geq 0
\end{gathered}
$$

The best and worst solution for the objective functions of the first level:

$$
f_{1}^{*}=1033.333 \quad \overline{f_{1}}=0
$$

B) Then the membership functions will be built using the value of $f_{1}^{*}, \overline{f_{1}}$, then using the membership functions of fuzzy set theory (2.15) and (2.16) will get the solution for the first level:

$\max \lambda$,

Subject to

$$
x \in G,
$$

$$
\begin{gathered}
X_{1}+X_{2}+X_{3}+X_{4}+X_{5}+X_{6}+X_{7}+X_{8} \\
-1033.333 \lambda \geq 0, \\
\lambda \in[0,1] .
\end{gathered}
$$

So, the solution is:

$\left(x_{1}^{f}, x_{2}^{f}, x_{3}^{f}, x_{4}^{f}, x_{5}^{f}, x_{6}^{f}, x_{7}^{f}, x_{8}^{f}\right)=$ $(0,0,0,33.333,0,0,0,171.333),\left(F_{11}^{f}\right)=$ (204.666)

$$
\lambda=0.2
$$

C) In this stage the best and worst solution for each objective function at the second level will solve the below equations individual:

$$
\begin{gathered}
\max _{X_{2}} F_{2} \approx\left[X_{2}+X_{4}+2 X_{5}+2 X_{6}+2 X_{7}\right. \\
\left.+2 X_{8}\right]
\end{gathered}
$$

Subject to

$$
\begin{gathered}
x_{5}+x_{6}+x_{7}+x_{8} \widetilde{\leq} 1000, \\
x_{1}+x_{2}+5 x_{5}+5 x_{6} \widetilde{\leq} 2800, \\
7 x_{1}+7 x_{2}+7 x_{3}+3 x_{5}+3 x_{6}+3 x_{7} \widetilde{\leq} 100, \\
x_{1}, x_{2}, x_{3}, x_{4}, x_{5}, x_{6}, x_{7}, x_{8} \geq 0
\end{gathered}
$$

The best and worst solution for the objective functions of the second level:

$$
f_{2}^{*}=2033.333 \quad \overline{f_{2}}=0
$$

D) the membership functions will build using the value of $f_{2}^{*}, \overline{f_{2}}$, then using the membership functions of fuzzy set theory (2.15) and (2.16) to get the solution for the second level:

$$
\max \beta \text {, }
$$

Subject to

$x \in G$,

$$
\begin{gathered}
X_{2}+X_{4}+2 X_{5}+2 X_{6}+2 X_{7}+2 X_{8} \\
-2033.333 \beta \geq 0 \\
\beta \epsilon[0,1] .
\end{gathered}
$$

So, the solution is:

$$
\begin{aligned}
& \left(x_{1}^{S}, x_{2}^{S}, x_{3}^{S}, x_{4}^{S}, x_{5}^{S}, x_{6}^{S}, x_{7}^{S}, x_{8}^{S}\right)= \\
& (0,0,0,0,0,33.333,0,170),\left(F_{2}^{f}\right)=(406.666)
\end{aligned}
$$


$\beta=0.2$

E) Consequently the best and worst solution for each objective function at the third level, will solve the below equations individual:

$$
\begin{gathered}
\max _{X_{5}} F_{3} \approx\left[X_{1}+X_{2}+X_{3}+X_{4}+4 X_{5}+4 X_{6}\right. \\
\left.+4 X_{7}+4 X_{8}\right]
\end{gathered}
$$

Subject to

$$
\begin{gathered}
x_{5}+x_{6}+x_{7}+x_{8} \widetilde{\leq} 1000, \\
x_{1}+x_{2}+5 x_{5}+5 x_{6} \widetilde{\leq} 2800, \\
7 x_{1}+7 x_{2}+7 x_{3}+3 x_{5}+3 x_{6}+3 x_{7} \widetilde{\leq} 100, \\
\quad x_{1}, x_{2}, x_{3}, x_{4}, x_{5}, x_{6}, x_{7}, x_{8} \geq 0
\end{gathered}
$$

The best and worst solution for the objective functions of the second level:

$$
f_{3}^{*}=4033.333 \quad \overline{f_{3}}=0
$$

F) The membership functions will be built using the value of $f_{3}^{*}, \overline{f_{3}}$, then using the membership functions of fuzzy set theory (2.15) and (2.16) to get the solution for the third level:

$\max \gamma$

Subject to

$$
\begin{gathered}
x \in G, \\
X_{1}+X_{2}+X_{3}+X_{4}+4 X_{5}+4 X_{6}+4 X_{7} \\
+4 X_{8}-4033.333 \gamma \geq 0 \\
\gamma \in[0,1] .
\end{gathered}
$$

So, the solution is:

$\left(x_{1}^{t}, x_{2}^{t}, x_{3}^{t}, x_{4}^{t}, x_{5,}^{t} x_{6}^{t}, x_{7}^{t}, x_{8}^{t}\right)=$

$(0,0,0,0,0,33.333,0,168.333)$,

$\left(F_{3}^{f}\right)=$

$(806.664)$

$\gamma=0.2$

The first level knows that using the optimal decision $\left(x_{1}^{f}\right)$ as a control variable for the second level are not practical. So, it needs some tolerance that gives the second level an extent feasible region to search for optimal solution and also reduce the search time.

So, new $x_{1}$ will be calculated and will be around with $\left(x_{1}^{f}\right)$ with maximum tolerance.

G) In order to generate the satisfactory solution with all satisfaction for all DMs. Having the following Tchebycheff problem:

\section{$\max \delta$,}

\section{Subject to}

$x_{5}+x_{6}+x_{7}+x_{8} \widetilde{\leq} 1000$,

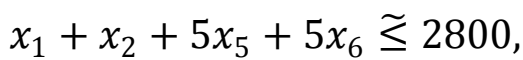

$$
\begin{aligned}
& 7 x_{1}+7 x_{2}+7 x_{3}+3 x_{5}+3 x_{6}+3 x_{7} \widetilde{\leq} 100 \\
& x_{1}, x_{2}, x_{3}, x_{4}, x_{5}, x_{6}, x_{7}, x_{8} \geq 0 \text {, } \\
& x_{1}-\delta \simeq-1 \text {, } \\
& x_{1}+\delta \widetilde{\simeq} 1 \text {, } \\
& x_{2}-\delta \geq-1 \text {, } \\
& x_{2}+\delta \stackrel{\simeq}{\leq} 1, \\
& X_{1}+X_{2}+X_{3}+X_{4}+X_{5}+X_{6}+X_{7}+X_{8} \\
& -1.333 \delta \geq 203.333 \text {, } \\
& X_{2}+X_{4}+2 X_{5}+2 X_{6}+2 X_{7}+2 X_{8} \\
& -3.334 \delta \geq 403.332 \text {, } \\
& X_{1}+X_{2}+X_{3}+X_{4}+4 X_{5}+4 X_{6}+4 X_{7} \\
& +4 X_{8}+6.668 \delta \geq 813.332 \text {, }
\end{aligned}
$$

(overall satisfaction for all DMs).

\section{SUMMARY AND COCNLUSION}

Based on these analytical results, it was concluded that every decision maker level reaches to a high satisfaction level $\delta=0.999$ regarding its goals and approaches. The first level decision maker i.e. Egyptian Ministry of Petroleum, its main goal is to increase the country production and reserves. This objective accelerated and attained by using the upstream gateway (EUG) for attracting the IOCs, Eni in this study, to invest more in Egypt to explore more producing wells and reach to new discoveries that consequently increasing the production and hydrocarbon reserves in Egypt.

Such innovative EUG project is considered as a long-term seven years project, there is an item indicated that; "the upstream data packages fees that paid by the IOCs for each concession included in each tender submitted by the Egyptian Ministry will be divided as follow: 55\% to the Egyptian Ministry and $45 \%$ to Schlumberger, i.e., second decision maker". On the other hand, this project opens a new opportunity for Schlumberger to apply their advanced software's and new technologies to re-process and enhance the old data for the interested IOCs.

EUG project will meet the third decision makers, i.e., IOCs, interest and satisfaction to minimize the cost and increase the success rate to find new additional oil and gas discoveries to increase their revenues. By submitting in the Egyptian tenders using the EUG they will access, acquire and evaluate the upstream data packages without need to come to Egypt and consequently minimize the cost. On the other hand, the enhanced re-processed data will increase the exploration success rate from $25 \%$ up to $50-60 \%$, this increases the probability to avoid the dry wells and increase the chance to drill producing wells that increase their income. Finally, this will increase the Egyptian hydrocarbon production that impact positively on Egypt economy and advancement plans. 


\section{ACKNOWLEDGMENTS}

I would like to express my gratitude and appreciation for Dr.Osama and Dr.Sayed for their guidance, support and encouragement throughout this study. I also wish to thank my family and colleges who have been a great source of support.

\section{REFERENCES}

[1] A, Adebayo, and B. Tawabini, "Hydrocarbon exploration and production-a balance between benefits to the society and impact on the environment.," J. Pet Environ. Biotechnol, vol. 3, no. 3, pp. 1-9, 2012.

[2] J. Dolson, "The Petroleum Geology of Egypt and History of Exploration," Springer International Publishing Switzerland, pp. 635-658, 2020.

[3] M. S. ,. H. Lyeme, "Introduction to Operations Research: Theory and Applications," LAP LAMBERT Academic PublishingISBN, pp. 635-658, 2012.

[4] H. Bhatia, C. Gupta, D.,0idi,H. Phallor, F. Shah,, "Operations Research in Manufacturing and Exports," International Journal of Advance Engineering and Research Development, 2017.

[5] M.S.Osman,M.A.Abo-Sinna, A.H.Amer,O.E.Emam "A multi-level non-linear multi-objective decision-making under fuzziness," Applied Mathematics and Computation, p. 239 252, 2004.

[6] Y. Yang, K. Pan, J. Liu, "A new approach for solving linear bilevel programming using differential evolution," Sixth International Conference on Genetic and Evolutionary Computing, 2012.

[7] S. L. Tilahun, S. M. Kassa , H. C. Ong, "A New Algorithm for Multilevel Optimization Problems Using Evolutionary Strategy, Inspired by Natural Adaptation," Conference Paper in Lecture Notes in Computer Science , 2012.

[8] M. S. Osman, O. E. Emam, M. A. El Sayed, "Multi-level multi-objective quadratic fractional programming problem with fuzzy parameters: A FGP approach.,"
Asian research journal of mathematics, vol. 5, no. 3, pp. 1-19, 2017.

[9] M.A.ElSayed,IbrahimA.Baky, Pitam Singh, "A modifed TOPSIS approach for solving stochastic fuzzy multi level multi objective fractional decision making problem," Operational Research Society of India, 2020.

[10] T. I. Sultan , O. E. Emam, A. A. Abohany, "A decomposition algorithm for solving a Three Level large scale linear programming problem.," Applied Mathematics \& Information Sciences, vol. 8, no. 5, pp. 2217-2223, 2014.

[11] K. \&. D. A. Lachhwani, "Bi-level and multi-level programming problems: taxonomy of literature review and research issues.," Archives of Computational Methods in Engineering, , vol. 25, no. 4, pp. 847-877, 2018.

[12] D, Moussa, S, Matbouly, "Nile Delta and North Sinai: fields, discoveries and hydrocarbon potentials, a comprehensive overview," The Egyptian General Petroleum Corporation, 1994.

[13] A. Samuel, B. Kneller, S. Raslan, A. Sharp, C. Parsons, "Prolific deep-marine slope channels of the Nile Delta, Egypt," Am Assoc Pet Geol Bull , p. 541-560, 2003.

[14] P. Boucher, J. Dolson, J. Siok, P. Heppard, "Key challenges to realizing full potential in an emerging giant gas province: Nile Delta/Mediterranean Offshore, Deep water, Egypt," Houston Geological Society, vol. 47, p. 25-27, 2004.

[15] A. Belopolsky, G. Tari , J. Craig, J. Illife, "New and emerging plays in the Eastern Mediterranean: an introduction.," Petroleum Geoscience, vol. 18, no. 4, pp. 371-372, 2012.

[16] A. Cozzi, "Zohr giant gas discovery: a paradigm shift in the Nile Delta and East Mediterranean exploration," AAPG/SEG ,nternational Conference and Exhibition, London, England,, p. 15-18, 2017. 